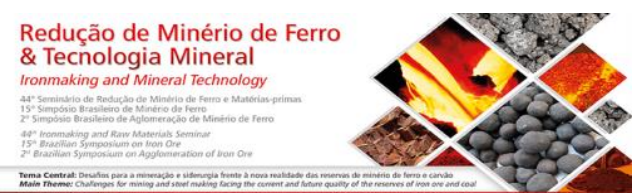

\title{
ENERGY-SAVING TECHNOLOGIES FOR BLAST FURNACES REALIZED BY NIPPON STEEL \& SUMIKIN ENGINEERING*
}

\author{
Kengo Usui \\ Norimasa Maekawa ${ }^{1}$ \\ Keisuke Morimitsu ${ }^{1}$ \\ Hironobu Ishikawa ${ }^{1}$ \\ Shin Tomisaki
}

\section{Abstract}

The energy consumption of Iron-making, especially Blast Furnace (BF), is very large. In order to maximize the utilization of limited resource, it is essential to reduce energy consumption and recovering waste energy in BF. This paper introduces energy saving equipment based on NSENGI's over 80 BF construction experiences since 1963. The first is the technology for the Top Charging System for low fuel-rate operation. One of the important factors to achieve such operation, the burden should be charged uniformly. Since 1974, NSENGI have developed and delivered over 80 Top Charging equipments for such purpose and nowadays, developed new type Top Charging equipment with improvement of charging precision. The second is the technology for Solely BFG Operation in Hot Stove, which means no use of other fuel gas such as LDG, COG. It is realized by high combustibility of NSENGI's Top-Combustion Hot Stove with Metallic Burners, and large amount of heat recovery of Waste gas Heat Recovery system with heat medium. The third is the technology for effective energy recovery in TRT. With NSENGI's latest Gas Cleaning System "Multi-Vessel Electrostatic Precipitator" (MVEP), TRT will be able to generate higher electrical energy by approx. $30 \%$ than that of wet-type. In comparison with dry bag-type, MVEP allows temperature fluctuation which lead to generate higher electrical energy by approx. $10 \%$ NSENGI therefore, will be able to accept and meet your request widely.

Keywords: Energy saving for blast furnace; Top charging system; Solely BFG operation; Multi-vessel electrostatic precipitator in gas cleaning system

1 Plant \& Machinery Division, Nippon Steel \& Sumikin Engineering CO., LTD, Kitakyushu-city, Fukuoka, Japan; usui.kengo@eng.nssmc.com.

Technical contribution to the $44^{\text {th }}$ Ironmaking and Raw Materials Seminar, $15^{\text {rd }}$ Brazilian Symposium on Iron Ore and $2^{\text {nd }}$ Brazilian Symposium on Agglomeration of Iron Ore, September $15^{\text {th }}$ to $18^{\text {th }}, 2014$, Belo Horizonte, MG, Brazil. 


\section{INTRODUCTION}

An interest in energy saving has been increasing in the world. Approximately $15 \%$ of energy consumption in the world is consumed by the steel industry and energy saving in this industry has large effect. Figure 1 shows the unit energy consumption required for iron and steel production in the main countries. In Brazil, there still remains room for fostering energy saving. Moreover, in the steel industry the rate of energy consumption in the iron-making process is close to $60 \%$ as shown in Figure 2. A reduced energy consumption in the iron-making process leads to a decrease in the amounts of coke and fuel gases that are used in iron production, which results in cost will be reduced.

Nippon Steel \& Sumikin Engineering (hereafter referred to as NSENGI) has constructed or relined more than 80 blast furnaces since 1963. In each project, NSENGI has not only delivered individual equipment, but also has engaged in from the basic study of iron-making process up to the detail design, manufacture, and construction of complete BF equipment. Variety of proposals can be provided based on affluent experience and technologies obtained through many projects. This paper introduces the energy-saving technologies and equipment of NSENGI.

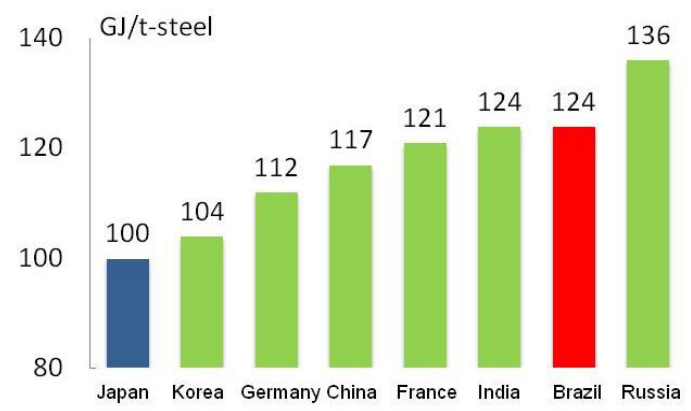

Figure 1 Unit energy consumption of iron and steel industry.

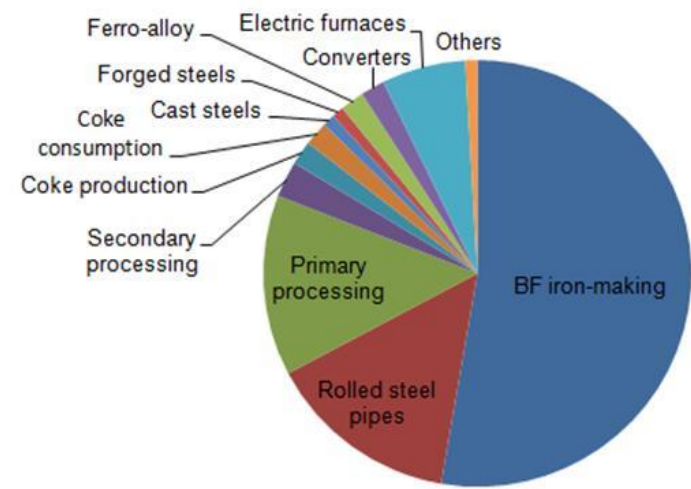

Fig. 2 Energy consumption on the basis of production process.

Technical contribution to the $44^{\text {th }}$ Ironmaking and Raw Materials Seminar, $15^{\text {rd }}$ Brazilian Symposium on Iron Ore and $2^{\text {nd }}$ Brazilian Symposium on Agglomeration of Iron Ore, September $15^{\text {th }}$ to $18^{\text {th }}, 2014$, Belo Horizonte, MG, Brazil. 


\section{DECREASE IN BF FUEL RATE $/ 5$ to $10 \%$ Coke Consumption will be Decreased, approx.110K tons annually.}

A reduced fuel rate in BF not only saves energy but also leads to a decrease of coal purchase costs. Fig. 3 shows the comparison of the gas utilization and productivity between NSENGI-constructed BFs and by other companies'. A higher gas utilization means reduction progresses efficiently in the furnace, which lowers the fuel rate.

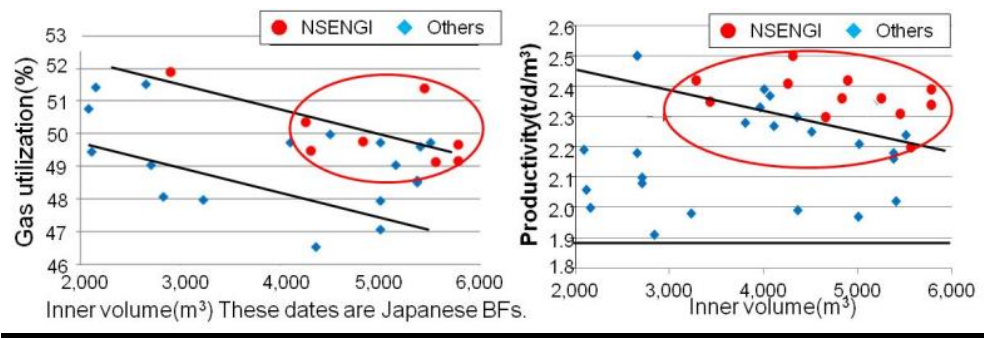

Fig. 3 Comparison of fuel rate and productivity between BFs of NSENGl's and others.

The BFs constructed by NSENGI offer high gas utilization and have been performing low fuel-rate operations, resulting in a high productivity coefficient. Particularly, the low fuel rate and high productivity $\left(2.20\left[\mathrm{t} / \mathrm{d} / \mathrm{m}^{3}\right]\right.$ or more $\left.]\right)$ are also maintained in large BFs whose Inner Volume(IV) exceeds $5,000 \mathrm{~m}^{3}$. (hereafter IV $5000 \mathrm{~m}^{3}$ class Blast furnace is assumed)

Figs. 4 and 5 show the gas flow under stable and unstable BF operations respectively. Points for achieving low fuel-rate and high productivity operations are as follows.

(1) Control gas flow uniform

(2) Achieving appropriate furnace-body cooling

The following describe our technologies for attaining above two points.

\subsection{Control Gas Flow Uniform}

To make the gas flow uniform, it is necessary following two points.

(1) Make a circumferentially uniform burden distribution in the furnace

(2) Provide a proper center gas flow

Fig. 4 shows an ideal furnace inner condition. The burden is distributed uniformly circumferentially and a center gas flow is provided. As a result, gas flow becomes uniform and an in-furnace reaction progresses efficiently, enabling low fuel-rate operations to be accomplished. In contrast, in Fig. 5 the burden is not uniform distribution and no center gas flow. Thus, gas flow are non-uniform, causing instable operation, which results in an increased fuel rate.

Technical contribution to the $44^{\text {th }}$ Ironmaking and Raw Materials Seminar, $15^{\text {rd }}$ Brazilian Symposium on Iron Ore and $2^{\text {nd }}$ Brazilian Symposium on Agglomeration of Iron Ore, September $15^{\text {th }}$ to $18^{\text {th }}, 2014$, Belo Horizonte, MG, Brazil. 


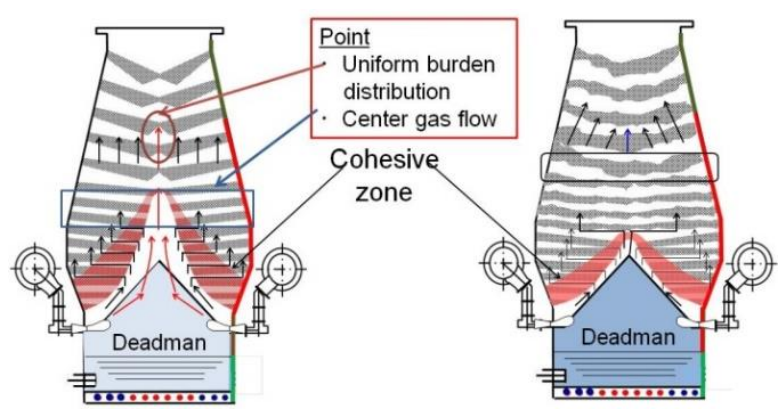

Fig.4 Ideal gas flow.

Fig. 5 Non-ideal gas flow.

\subsubsection{Technology for making gas flow uniform}

Since 1974, NSENGI has been delivered more than 80 units of top charging equipment and has also been continuously making improvements to make in-furnace gas flow uniform circumferentially and provide a center gas flow.

Fig. 6 shows the flow of materials from the Receiving hoppers to chutes and then to the furnace inside of the conventional top charging equipment. As shown in Fig. 6-(A), materials are charged into the furnace lopsidedly because there is generally the horizontal component of the velocity in parallel hoppers. However, NSENGI has the technology of preventing inertia-caused uneven flows from being created and of charging materials into the furnace uniformly circumferentially as shown in Figure 6-(B). In addition, for the particle sizes of the materials to be discharged from the hoppers, fine particles are discharged first and coarse particles are fed later. As shown in Figure 7-(A), an occurrence of time-series size segregation of the material causes finer particles to be apt to be concentrated at the furnace center, making a center gas flow weaker. NSENGI has the technology of controlling material flows so that the distribution of the particle size is constant in time series at the hopper outlets as shown in Figure 7-(B). Therefore, size segregation in the radial direction in the furnace is eliminated, enabling the gas flow to be distributed as shown in Figure 4.
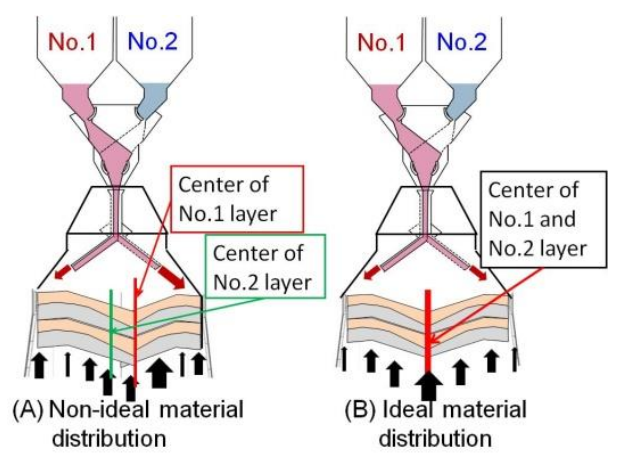

Fig.6 Change in in-furnace material istributio by improvement of top chargingquipment.

Technical contribution to the $44^{\text {th }}$ Ironmaking and Raw Materials Seminar, $15^{\text {rd }}$ Brazilian Symposium on Iron Ore and $2^{\text {nd }}$ Brazilian Symposium on Agglomeration of Iron Ore, September $15^{\text {th }}$ to $18^{\text {th }}, 2014$, Belo Horizonte, MG, Brazil. 

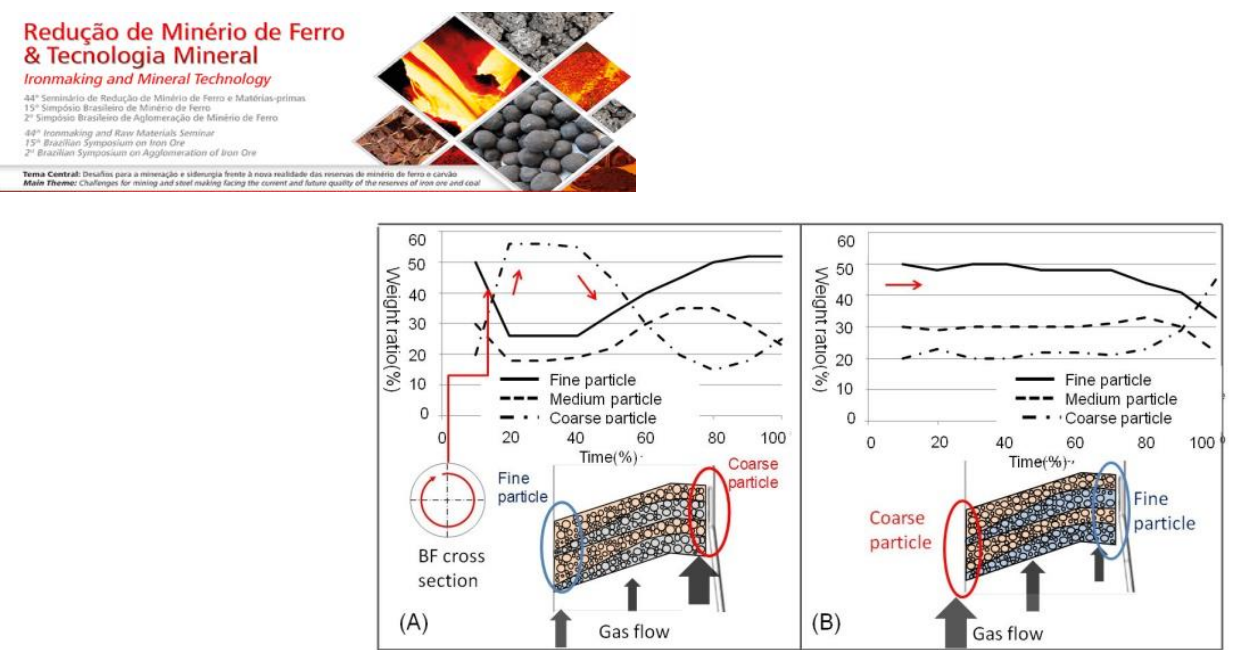

Fig. 7 Time-series change in the particle size of materials discharged from hoppers and their in-furnace distribution.

\subsubsection{Advanced top charging equipment}

To make gas flow further uniform and provide a center gas flow, NSENGI proposes an NSENGI-advanced Top Charging Equipment based on experience and technologies attained from a lot of delivery records. Figure 8 shows the advanced top charging equipment. In this equipment, the rotating speed of the chute has improved to $12 \mathrm{rpm}$, 1.5 times that of conventional type due to weight reduction of the rotating section such as the chutes and a reduced moment of inertia. Moreover, the tilting speed becomes three times faster, providing a very high response. Therefore, the advanced top charging equipment can support a variety of material distribution methods. Furthermore, the chute contour was improved so that the material does not disperse, improving the distribution accuracy of central coke charging. As a result, further uniform gas flow and the formation of a center gas flow are accomplished. In addition, the conventional type required more than 11 gears to perform tilting, but the advanced top charging equipment has only three gears by simplifying the mechanics. The simplification of the construction enables the material falling height to be lower by $1 \mathrm{~m}$. This reduces the pulverization of the material due to crash, preventing draft from getting worse. Moreover, the advanced type costs less than the conventional type and has achieved weight decrease. And lowering the loads applied to rotating bearings by approx. $30 \%$, which is received a risk of failure in the rotating bearings to be reduced.

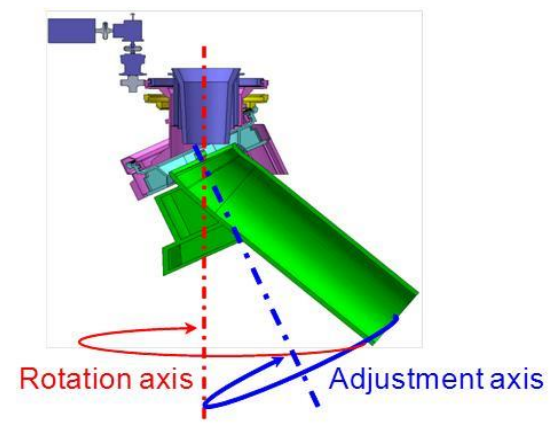

Fig. 8 Advanced top charging equipment.

Technical contribution to the $44^{\text {th }}$ Ironmaking and Raw Materials Seminar, $15^{\text {rd }}$ Brazilian Symposium on Iron Ore and $2^{\text {nd }}$ Brazilian Symposium on Agglomeration of Iron Ore, September $15^{\text {th }}$ to $18^{\text {th }}, 2014$, Belo Horizonte, MG, Brazil. 


\subsection{Optimization of furnace-body cooling}

For furnace-body cooling, the furnace body is divided into zones as shown in Fig. 9 and appropriate cooling is provided on each zone basis. At the upper part of the furnace, excessive cooling causes the temperature rise of the burden to be slow, resulting in a delay in reduction reaction in the furnace. Therefore, by separating the strong cooling zone, the upper part of the furnace is gently cooled. We propose optimal furnace-body cooling for each zone based on such concept.

A combination of NSENGI's Top Charging Equipment and Furnace-Body Cooling Equipment allows the fuel rate to be reduced by 5 to $10 \%$, which enables the amount of coke consumption to be cut down by $110 \mathrm{~K}$ tons annually.

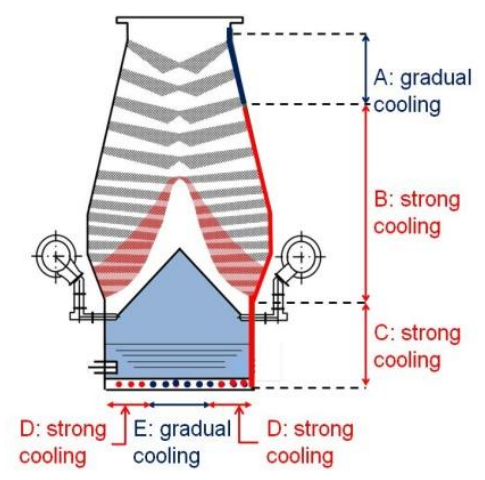

Fig.9 BF body cooling system.

\section{THE ENERGY-SAVING TECHNOLOGY USING HOT STOVE WASTE GAS HEAT RECOVERY SYSTEM}

\subsection{Merits of the Waste Gas Heat Recovery System}

\subsubsection{Merits of NSENGI's waste gas heat recovery system with heat medium decrease of the COG consumption by $50 \%$, of $76 \times 10^{6} \mathrm{Nm}^{3}$ annually}

Fuel gas used in a hot stove is mainly the blast furnace gas (BFG) with additional gas of high calorie such as COG and LPG are used together. And, the hot stove's combustion waste gas has high temperatures as approx. $300^{\circ} \mathrm{C}$ and high thermal energy, but is discharged into the air through stack. Recovering this discharged energy to preheat the fuel gas and combustion air allows the of the fuel gas and combustion air, which contributes to a decrease high calorie-gas consumption, therefore running cost of HS is reduced. Fig. 10 shows the gas flow diagram without waste gas heat recovery system and Fig. 11 shows the gas flow of NSENGl's Waste gas Heat Recovery System with heat medium (hereafter referred to as NSENGI HRS). NSENGI HRS consists of a heat exchanger for receiving heat from the waste gas (1) Technical contribution to the $44^{\text {th }}$ Ironmaking and Raw Materials Seminar, $15^{\text {rd }}$ Brazilian Symposium on Iron Ore and $2^{\text {nd }}$ Brazilian Symposium on Agglomeration of Iron Ore, September $15^{\text {th }}$ to $18^{\text {th }}, 2014$, Belo Horizonte, MG, Brazil. 
in Fiure 11), heat exchangers for heating the fuel gas and combustion air (2) and (3) in Figure 11), and a temperature control value that controls heat medium temperature (4) in Figure 11). It transfers heat recovered by the heat medium oil to preheat the fuel gas and combustion air.

The adoption of NSENGI HRS shown in Figure 11 enables an annual COG $76 \times 10^{6}$ $\mathrm{Nm}^{3}$ to be reduced, equivalent to approx. $50 \%$ of COG consumption.

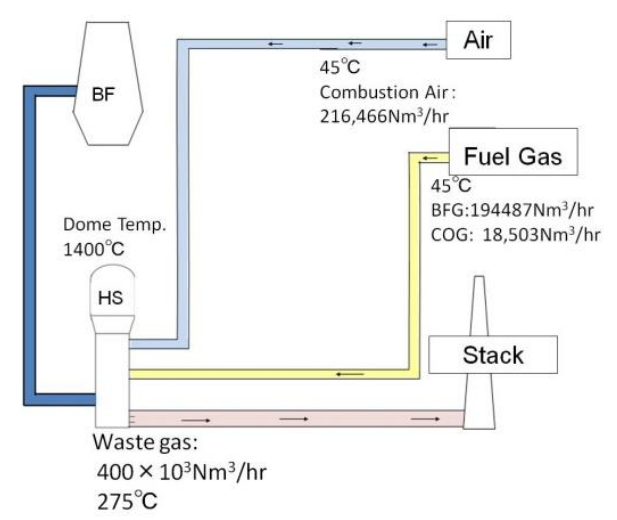

Fig.10 without waste gas heat recovery system

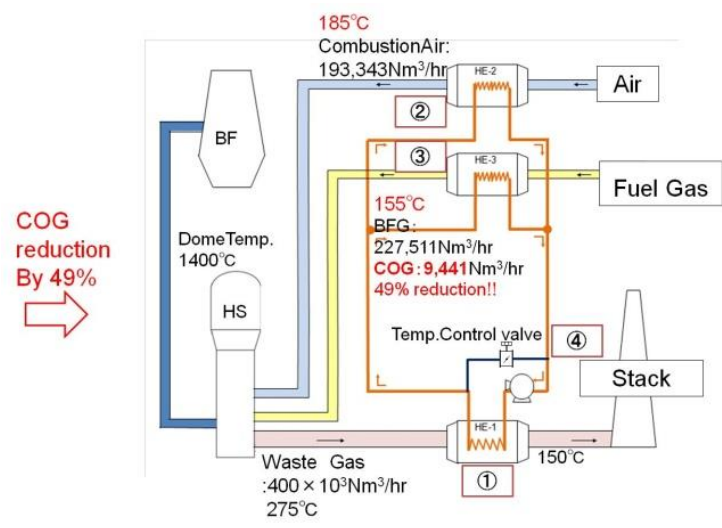

Fig. 11 NSENGI HRS

\subsubsection{Comparison with the heat pipe type the amount of COG consumption is smaller by $6.6 \times 10^{6} \mathrm{Nm}^{3}$ annually}

Figure 12 shows gas flow of the waste gas heat recovery system of the heat pipe type. The heat pipe type preheats fuel gas and combustion air by connecting a waste gas duct and fuel gas and combustion air ducts to the heat exchangers of combined heat receiving and heating type (1) and (2) in Figure 12) to conduct heat exchange. The comparison of the amounts of heat recovery between NSENGI HRS and heat pipe types is shown in Table 1.

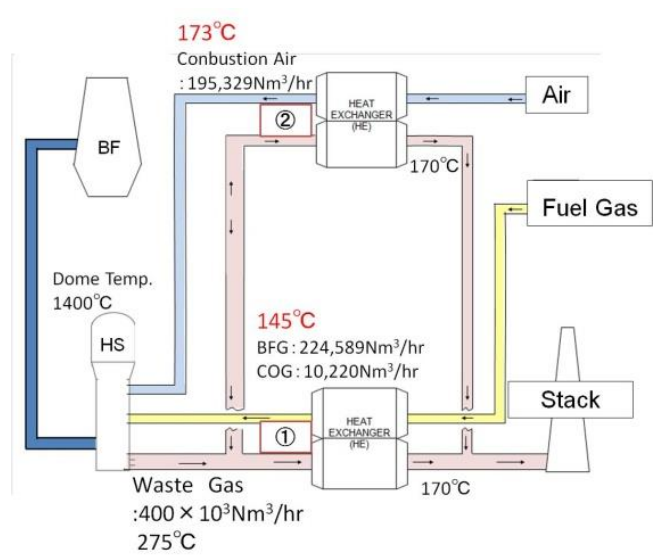

Fig.12 heat pipe type waste-gas heat recovery system

Technical contribution to the $44^{\text {th }}$ Ironmaking and Raw Materials Seminar, $15^{\text {rd }}$ Brazilian Symposium on Iron Ore and $2^{\text {nd }}$ Brazilian Symposium on Agglomeration of Iron Ore, September $15^{\text {th }}$ to $18^{\text {th }}, 2014$, Belo Horizonte, MG, Brazil. 
Because hot stove waste gas contains minute quantity of SOx and moisture, an excessive recovery of heat by use of a heat-receiving heat exchanger installed in the flue causes the waste gas temperature to fall below the acid dew point (ADP); sulfuric acid condensates on the finned tube surface to corrode the finned tube seriously.

For the heat pipe type, the amount of heat recovery cannot be controlled. Thus, the finned tube surface areas of the heat exchanger must be designed in accordance with the minimum waste gas temperature so that the finned tube surface temperature does not fall below the acid dew point. Therefore the amount of heat recovery is limited even if the waste gas temperature rises. The yellow area

Table 1 Comparison of heat recovery between NSENGI heat medium type and heat pipe type

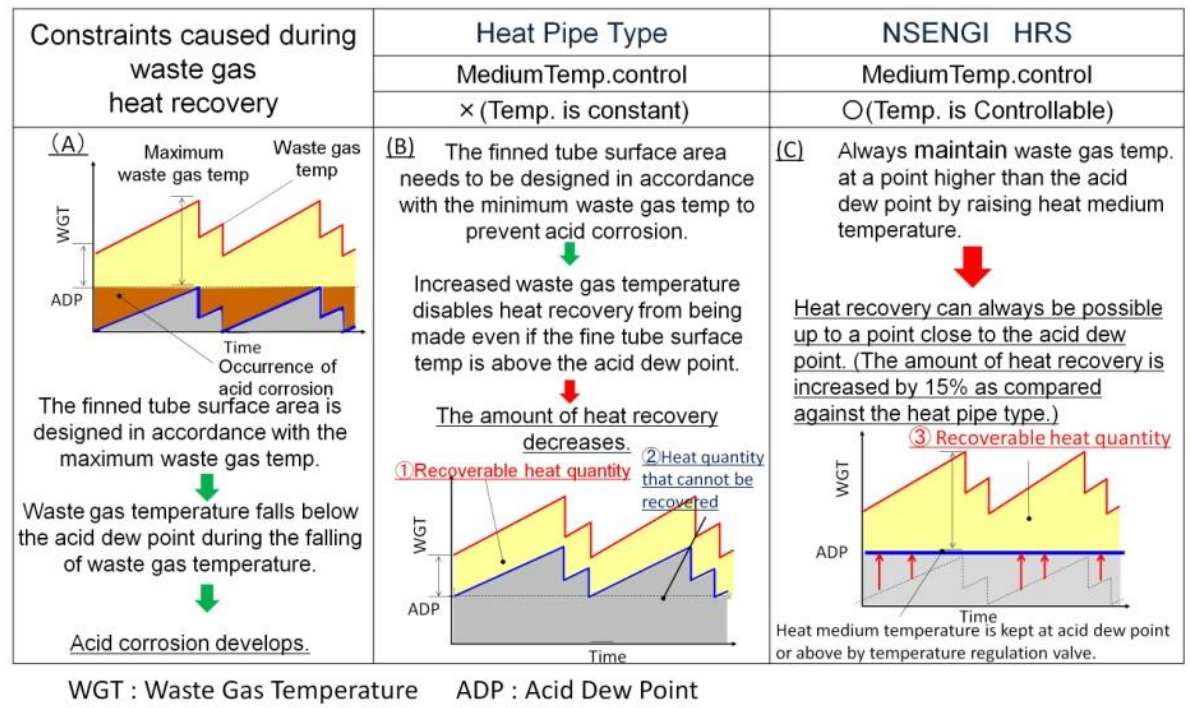

(1) in field (B) in Table 1 show the amount of heat recovery of heat pipe type. And no heat recovery can be made in area (2). In contrast, NSENGI HRS can control the temperature of the heat medium that passes through each heat exchanger by operating the temperature control valve the finned tube surface temperature can always be maintained to a point above the ADP easily, even if the waste gas temperature is fluctuated. This enables the amount of heat recovery to be available in yellow area (3) in field (C) in Table 1. Therefore, NSENGI HRS offers the amount of heat recovery approx. 15\% higher than that of the heat pipe type and the amount of COG required to attain the same dome temperature os $\mathrm{HS}$ is smaller in NSENGI heat medium type than the HRS. Decrease in COG consumption is approx. $6.6 \times 10^{6}$ $\mathrm{Nm}^{3}$ annually.

Technical contribution to the $44^{\text {th }}$ Ironmaking and Raw Materials Seminar, $15^{\text {rd }}$ Brazilian Symposium on Iron Ore and $2^{\text {nd }}$ Brazilian Symposium on Agglomeration of Iron Ore, September $15^{\text {th }}$ to $18^{\text {th }}, 2014$, Belo Horizonte, MG, Brazil. 


\subsection{Solely BFG Operation/COG Consumption can be Reduced to "0."}

By the adoption of a waste gas heat recovery system, consumption of high calorie gas can be reduced additionally, by preheating the BFG and combustion air further, it is possible to achieve the specified dome temperature only with BFG. If an operation using only BFG is possible (hereafter referred to as solely BFG operation), the high calorie gas is not necessary and significant cost reduction merits can be acquired. Table 2 shows the results of solely BFG operation in the hot stove for BF with a furnace IV of $1,350 \mathrm{~m}^{3}$. Conventionally, 1,120 [ $\left.\mathrm{Nm}^{3} / \mathrm{hr}\right]$ of LPG was added as fuel gas. However, the adoption of NSENGl's HRS has enabled the amount of LPG consumption to be "0."

Table 2 Merits acquired by solely BFG combustion

\begin{tabular}{|l|c|c|}
\hline & WithoutHRS & NSENGl's HTM-type HRS \\
\hline BFG temp. [C] & 35 & 250 \\
\hline Combustion air temp. [C] & 45 & 250 \\
\hline BFG rate $\left[\mathrm{Nm}^{3} / \mathrm{h}\right]$ & 51,900 & 75,100 \\
\hline Combustion air rate $\left[\mathrm{Nm}^{3} / \mathrm{h}\right]$ & 69,000 & 53,500 \\
\hline LPG rate[Nm $\left.{ }^{3} / \mathrm{h}\right]$ & 1,120 & 0 \\
\hline
\end{tabular}

\subsubsection{Superiority of NSENGI heat medium type in solely BFG operation}

Fig. 13 shows the gas flow in the case of solely BFG operation by NSENGI HRS and Fig. 14 shows the gas flow in the case of solely BFG operation by the heat pipe type. To realize a solely BFG operation, BFG and combustion air are preheated further by use of an additional burner of (1) in Fig. 13 and (1) in Fig. 14. In the operation by NSENGI HRS, the temperature of heat medium is raised by the waste gas of the additional burner directory, and the heated heat medium heated BFG, and Air additinary BFG and combustion air are preheated. Furthermore, the additional burner waste gas mixes with the hot stove waste gas and preheats the BFG and combustion air via the heat-conveying heat exchangers. On the other hand, in the operation by heat pipe type, the waste gas from the additional burner is mixed with hot-stove waste gas, and their heats are exchanged by a heat exchanger of heat-receiving/conveying type, by which the temperatures of BFG and combustion air are raised. In comparison with other heat pipe types, NSENGI heat medium type has the following merits. The reasons are as follows.

Technical contribution to the $44^{\text {th }}$ Ironmaking and Raw Materials Seminar, $15^{\text {rd }}$ Brazilian Symposium on Iron Ore and $2^{\text {nd }}$ Brazilian Symposium on Agglomeration of Iron Ore, September $15^{\text {th }}$ to $18^{\text {th }}, 2014$, Belo Horizonte, MG, Brazil. 
3.2.1.1 BFG consumption by additional burning is $92 \times 10^{6} \mathrm{Nm}^{3}$ smaller annually. No aged degradation allows continuation of solely BFG operation

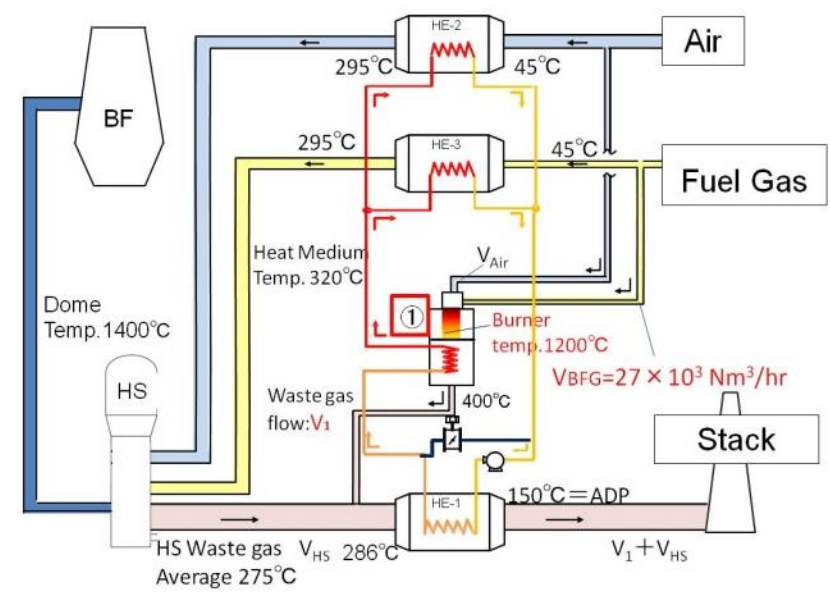

Fig. 13 Solely BFG operation by NSENGI heat medium type.

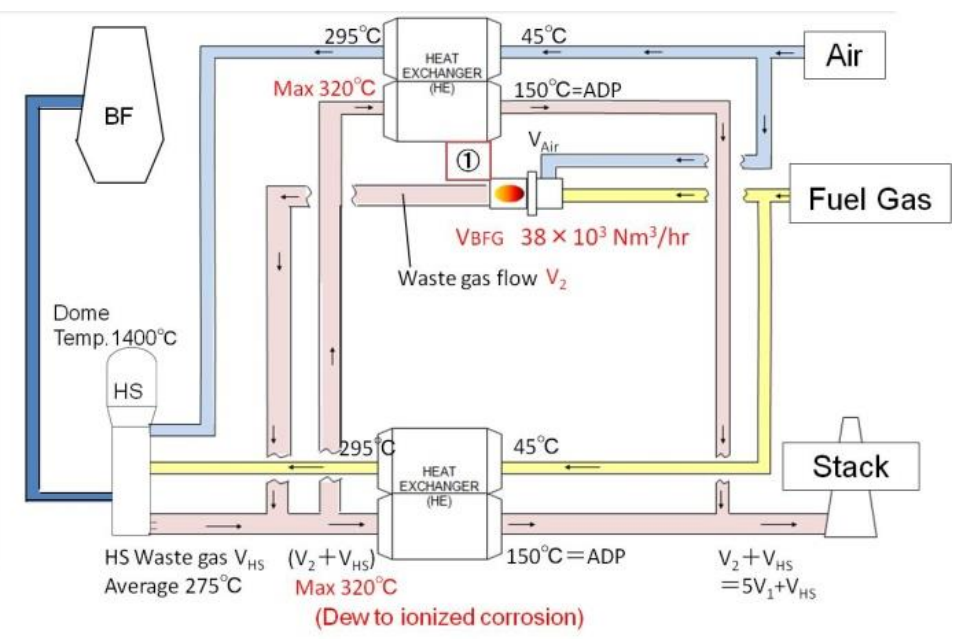

Fig. 14 Solely BFG operation by heat pipe type

\subsubsection{BFG consumption by additional burner is $92 \times 10^{6} \mathrm{Nm}^{3}$ smaller annually}

Table 3 shows the comparison of BFG temperature raising process by the additional burner between NSENGI HRS and heat pipe type. The heat pipe type uses water as the heat medium. When the steam temperature exceeds $300^{\circ} \mathrm{C}$, water is ionized to induce ionizing corrosion, which deteriorates the finned tube. Thus, the waste gas temperature at the inlet of heat exchanger at heat-receiving side is limited to approximately $320^{\circ} \mathrm{C}$, and the temperature of additional waste gas must be lowered by increasing the fuel-air ratio.

Technical contribution to the $44^{\text {th }}$ Ironmaking and Raw Materials Seminar, $15^{\text {rd }}$ Brazilian Symposium on Iron Ore and $2^{\text {nd }}$ Brazilian Symposium on Agglomeration of Iron Ore, September $15^{\text {th }}$ to $18^{\text {th }}, 2014$, Belo Horizonte, MG, Brazil. 


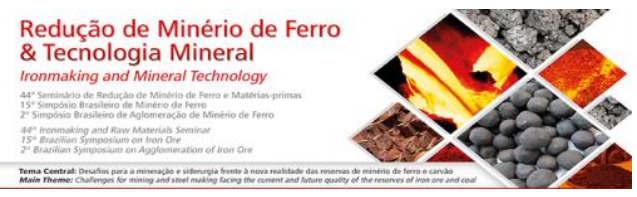

Table 3 Comparison of additional burning system between heat medium type and heat pipe type

\begin{tabular}{|c|c|c|}
\hline & 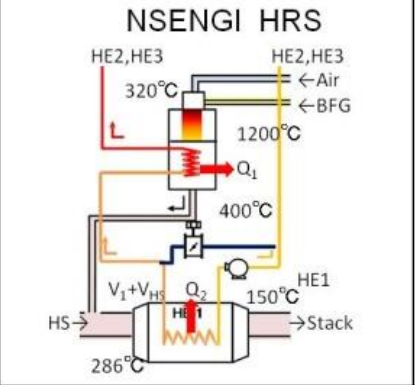 & Heat Pipe type \\
\hline Flow control & O & $\times \quad$ No Flow control \\
\hline $\begin{array}{l}\text { Heat quantity } Q \text { For } \\
\text { preheating by additional } \\
\text { burning }\end{array}$ & $\begin{array}{l}\mathrm{Q}=\mathrm{Q}_{1}+\mathrm{Q}_{2}= \\
\Delta \mathrm{t}_{1} \times \mathrm{Cp}_{1} \times \mathrm{V}_{1}+\frac{\Delta \mathrm{t}_{2}}{1} \times \mathrm{CP}_{2} \times\left(\mathrm{V}_{1}+\mathrm{V}_{\mathrm{HS}}\right) \\
\left(1200^{\circ} \mathrm{C}-400^{\circ} \mathrm{C}\right)\left(286^{\circ} \mathrm{C}-150^{\circ} \mathrm{C}\right)\end{array}$ & $\begin{array}{c}\mathrm{Q}=\mathrm{Q}_{3}=\Delta \mathrm{t}_{3} \times \mathrm{Cp}_{3} \times\left(\mathrm{V}_{2}+\mathrm{V}_{\mathrm{HS}}\right) \\
=\mathrm{Q}_{1}+\mathrm{Q}_{2} \uparrow \\
\quad\left(320^{\circ} \mathrm{C}-150^{\circ} \mathrm{C}\right)\end{array}$ \\
\hline $\begin{array}{l}\text { Waste gas produced } \\
\text { by additional burning }\end{array}$ & $V_{1}$ (Base) & $\mathrm{V}_{2}=\frac{\Delta \mathrm{t}_{1} \times C \mathrm{p}_{1}}{\Delta \mathrm{t}_{3} \times \mathrm{Cp}_{3}} \times \mathrm{V}_{1}\left(\fallingdotseq 5 \mathrm{~V}_{1}\right)$ \\
\hline $\begin{array}{l}\mathrm{BFG} \text { used by additional } \\
\text { burning burner } \mathrm{V}_{\mathrm{BFG}}\end{array}$ & $27 \times 10^{3}\left[\mathrm{Nm}^{3} / \mathrm{hr}\right]$ & $38 \times 10^{3}\left[\mathrm{Nm}^{3} / \mathrm{hr}\right]$ \\
\hline
\end{tabular}

On the other hand, because NSENGI HRS can control the heat medium flow rate to regulate its temperature, and can use waste gas of additional burner directly (approx. $1200^{\circ} \mathrm{C}$ ). The heat quantity required for raising the temperature of BFG and combustion air recovered by additional burning is equal between NSENGI HRS and heat pipe types. However, as shown in Table 3, because the difference in the temperature at the inlet and outlet of heat exchanger is small in the case of heat pipe type, the temperature of hot stove waste gas must be raised up to $320^{\circ} \mathrm{C}$ in order to obtain the same heat quantity, which requires more waste gas or BFG for producing the waste gas than the NSNEGI HRS. As shown in Figs. 13 and 14, when temperatures of BFG and combustion air are raised to $295^{\circ} \mathrm{C}$, and the amount of BFG used by the additional burner in the case of heat medium type is $92 \times 10^{6} \mathrm{Nm}^{3}$ smaller annually than that of the heat pipe type.

\subsubsection{Free from aged deterioration and continuation to perform solely BFG operation for a long duration}

In the heat pipe type, the function of the heat exchangers degrades and the amount of heat recovery decreases due to the aged deterioration of external surface, etc. because ionizing corrosion is liable to occur in the finned tube. Therefore the preheating of BFG and combustion air becomes insufficient to disable the continuation of solely BFG operation. As shown in Fig. 15, there is an actual example of $20 \%$ to $40 \%$ drop in the fuel gas and combustion air temperatures at the heat exchanger outlets after five years. To maintain the dome temperature, it is necessary to add a high-calorie gas such as COG and, as shown in the example, $59 \times 10^{6}\left[\mathrm{Nm}^{3}\right.$ /yea]r of COG is required five years later. On the other hand, NSENGI heat medium

Technical contribution to the $44^{\text {th }}$ Ironmaking and Raw Materials Seminar, $15^{\text {rd }}$ Brazilian Symposium on Iron Ore and $2^{\text {nd }}$ Brazilian Symposium on Agglomeration of Iron Ore, September $15^{\text {th }}$ to $18^{\text {th }}, 2014$, Belo Horizonte, MG, Brazil. 
type is free from ionizing corrosion and controls the flow rate of the heat medium, so that the heat exchangers can be operated at temperatures at which the heat medium does not deteriorate. Thus, solely BFG operation can be continued for a long duration and $C O G$ addition as in the example of the heat pipe type is not required. Adding the merits of decrease the BFG consumption by additional burning and no occurrence of aged deterioration, the yearly energy consumption of NSENGI heat medium type becomes $14 \times 10^{3} \mathrm{GJ}$ smaller than that of the heat medium type five years later.

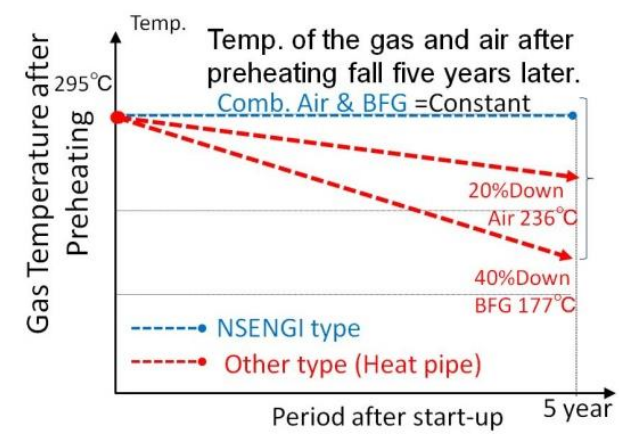

Fig.15. Falling of preheated temperatures of fuel gas and combustion air due to aged deterioration

\subsection{NSENGl's Top Combustion Hot Stove Suitable for Solely BFG Operation The Unburned CO is Low, Energy Consumption to be Reduced By $7.1 \times 10^{3} \mathrm{GJ}$ Annually}

The burners are required to provide high combustibility. But BFG is gas that is difficult to burn. Fig. 16 shows NSENGI-advanced Top Combustion Hot Stove with Metallic Burners. Fig. 17 shows the diagrams of the analytical comparis on of combustibility from the results in Fig. 17 that only NSENGI-designed Top Combustion Hot Stove with Metallic Burners can provide high combustibility with less unburned $\mathrm{CO}$ even in the case of solely BFG operation. The amount of energy consumption can be reduced by $7.1 \times 10^{3}$ GJ annually.

This is equivalent to an annual decrease $2.4 \times 10^{6} \mathrm{Nm}^{3} \mathrm{BFG}$.

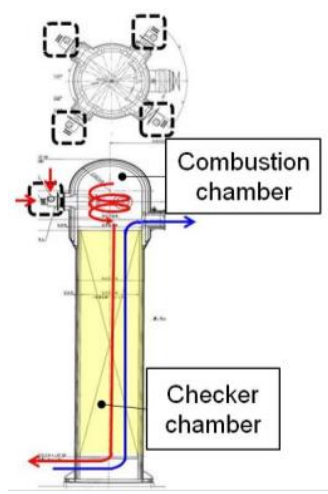

Fig.16 NSENGI's top combustion hot stove

Technical contribution to the $44^{\text {th }}$ Ironmaking and Raw Materials Seminar, $15^{\text {rd }}$ Brazilian Symposium on Iron Ore and $2^{\text {nd }}$ Brazilian Symposium on Agglomeration of Iron Ore, September $15^{\text {th }}$ to $18^{\text {th }}, 2014$, Belo Horizonte, MG, Brazil. 


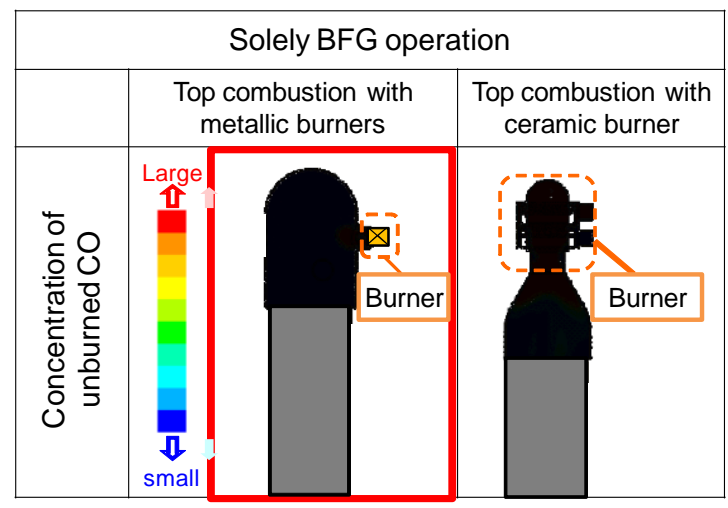

Fig.17 Comparison of burner combustibility

\section{GAS CLEANING SYSTEM SUITABLE FOR EFFICIENT ENERGY RECOVERY}

\subsection{General Outline of Various Gas Cleaning Systems}

The gas cleaning system is classified into four types depending on the dust-collecting methods: (1) Wet type, (2) Wet type (Electrostatic Precipitaor), (3) Dry-type bag filters, and (4) Dry-type Multi-Vessel Electrostatic Precipitator (hereafter referred to as MVEP). In addition, by the top-gas pressure recovery turbine (TRT) adoption the downstream of this equipment, the pressure and temperature energy of top gas is recovered as electric power. As a result, it is required to minimize the drops in gas pressure and temperature during gas cleaning from the viewpoint of energy saving. The following describes the overview of each gas cleaning system.

(1)The wet-type gas cleaning system which spraying water to top gas.

(2) The wet-type gas cleaning system is a method in which electrode plates are added to the noted wet-type gas cleaning system to perform dust collection.

(3)The dry-type gas cleaning system. This method removes dust in top gas using bag filters. On the other hand, the bag filter type can only be used within a specific temperature range due to the limitation of usable temperature.

(4)NSENGI's original dry MVEP that solves this problem and decreases the pressure loss. The features of the each system, pressure loss, temp drop, the amount of electricity generation at TRT, and the amount of energy recovery are as described in Table 4. NSENGI can engineer all four types of the gas cleaning systems. The following introduces (4) dry-type MVEP that particularly offers high energy-saving effect.

Technical contribution to the $44^{\text {th }}$ Ironmaking and Raw Materials Seminar, $15^{\text {rd }}$ Brazilian Symposium on Iron Ore and $2^{\text {nd }}$ Brazilian Symposium on Agglomeration of Iron Ore, September $15^{\text {th }}$ to $18^{\text {th }}, 2014$, Belo Horizonte, MG, Brazil. 


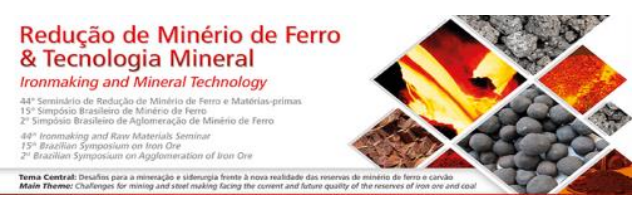

Table 4 Comparison of the gas cleaning system

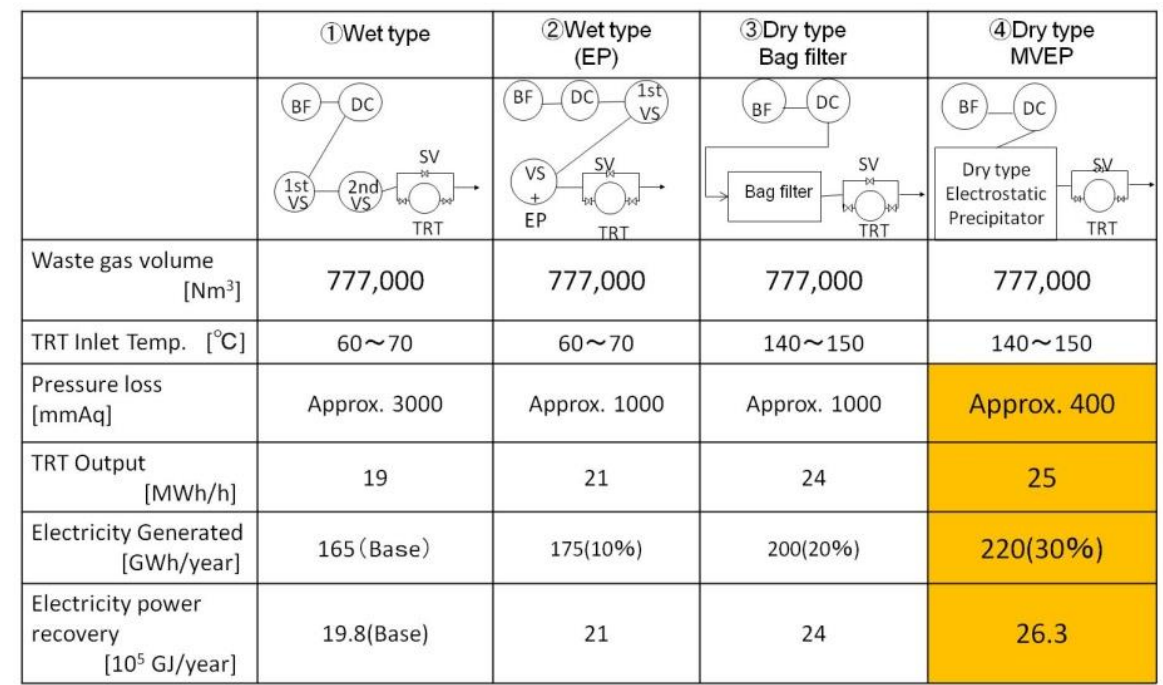

\subsection{Multi-Vessel Electrostatic Precipitator Dry Type the Amount of Electricity Generation At TRT is Improved By 30\%, Enabling the Amount Of Energy Consumption to be Reduced by $6.5 \times 10^{6}$ GJ Annually}

Figure 20 shows the gas flow of NSENGl's Multi-Vessel Electrostatic Precipitator (dry type) (MVEP). Since its delivery in 1985, the MVEP has applied the technologies of the wet-type (EP) gas cleaning system that have operation records. The dust collection method is such that when high voltage is applied to the electrode to generate corona discharge, particles in gas flow are electrically charged and there occurs a potential difference between the electrode and precipitator plate, causing dust to be collected as shown in the schematic diagram in Fig. 18. The MVEP suffers a pressure loss as small as approx. $400 \mathrm{mmAq}$ and can deal with a top-gas temperature of up to $350^{\circ} \mathrm{C}$ (TRT inlet temp: 140 to $150^{\circ} \mathrm{C}$ ). As a result, the amount of electricity generation at TRT is $25 \mathrm{MWh} / \mathrm{hr}$, which allows the amount of TRT electricity generation to be improved by approx. 30\% annually in comparison with the wet-type gas cleaning system (a decrease of energy consumption is approx. $6.5 \times 10^{5} \mathrm{GJ}$ annually). Moreover, it is still $10 \%$ higher than that of the bag filter type (a decrease of energy consumption is approx. $2.3 \times 10^{5} \mathrm{GJ}$ a year). In addition, MVEP eliminates the need for frequent replacement of bag filters in the case of bag filter type, which also offers the merit of lower maintenance costs.

Technical contribution to the $44^{\text {th }}$ Ironmaking and Raw Materials Seminar, $15^{\text {rd }}$ Brazilian Symposium on Iron Ore and $2^{\text {nd }}$ Brazilian Symposium on Agglomeration of Iron Ore, September $15^{\text {th }}$ to $18^{\text {th }}, 2014$, Belo Horizonte, MG, Brazil. 

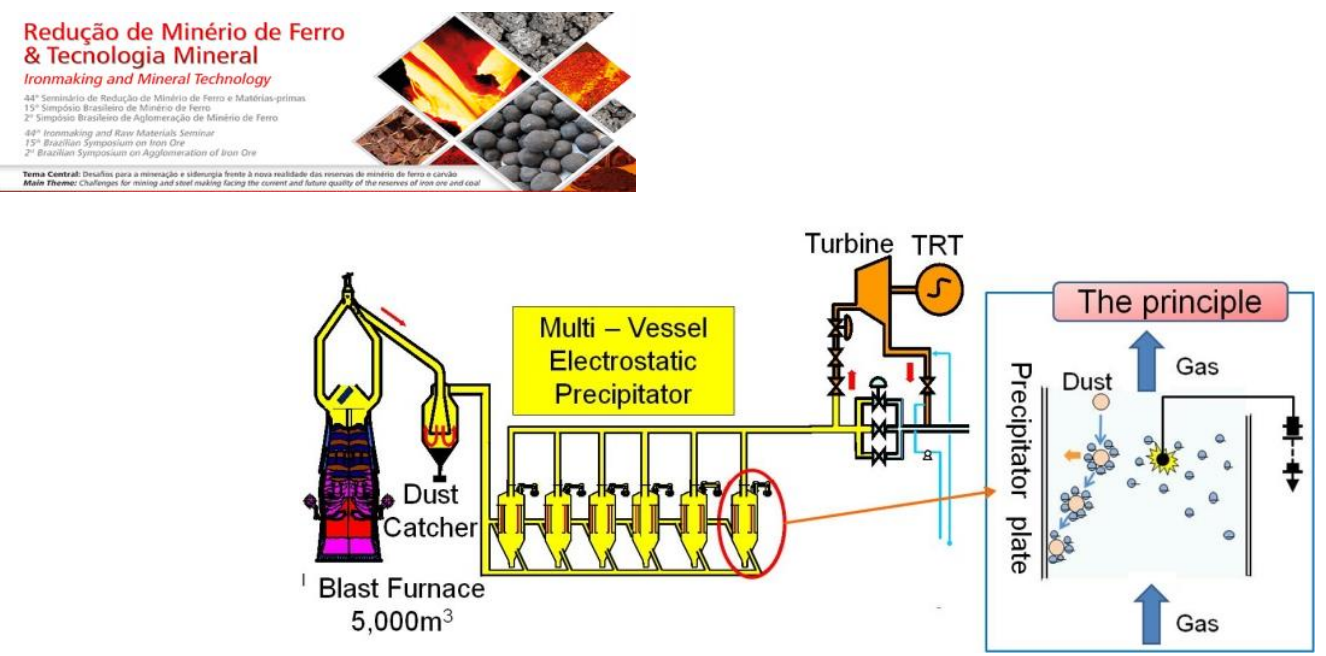

Fig.18 Falling of preheated temperatures of fuel gas and combustion air due to aged deterioration

The comparison of electricity recovery between MVEP and bag filter type is shown in Fig. 19. Because the bag filter type can only be used within the temperature range of 70 to $200^{\circ} \mathrm{C}$, the gas temperature must be lowered by water spraying equipment installed upstream. At this time, however, the temperature and pressure of gas drop to decrease the TRT output. In contrast, the MVEP can recover electricity up to the durable temperature of steel shell, and the amount of energy recovery is approximately $10 \%$ higher than that of the bag filter type.

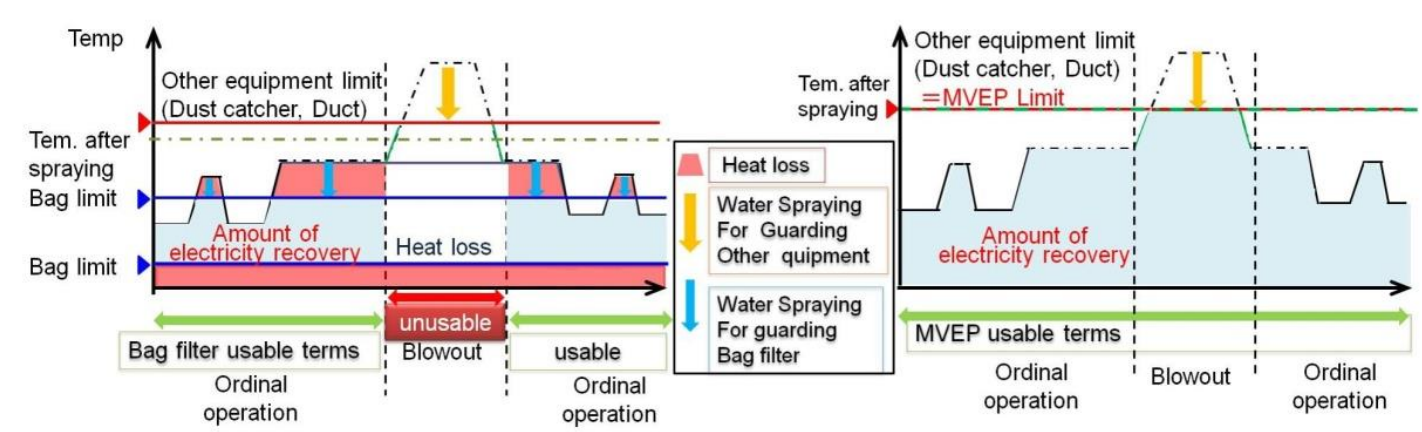

Figure 19 Comparison of electricity recovery between dry bag filter type and MVEP

\section{CONCLUSION}

The adoption of the systems and equipment described in this paper enables the following energy-saving effect to be attained and consequently, cost reduction to be expected.

$>$ low fuel-rate top charging equipment

- decrease in the fuel rate by 5 to $10 \%$,

- coke consumption to be reduced by $110 \mathrm{~K}$ tons annually.

$>$ NSENGl's waste gas heat recovery system

- COG consumption is reduced by $76 \times 10^{6} \mathrm{Nm}^{3}$ annually.

- Compared with the heat pipe in solely BFG operations,

No ionized corrosion and aged deterioration

Yearly energy consumption is cut down by $14 \times 10^{5}$ GJ five years later.

Technical contribution to the $44^{\text {th }}$ Ironmaking and Raw Materials Seminar, $15^{\text {rd }}$ Brazilian Symposium on Iron Ore and $2^{\text {nd }}$ Brazilian Symposium on Agglomeration of Iron Ore, September $15^{\text {th }}$ to $18^{\text {th }}, 2014$, Belo Horizonte, MG, Brazil. 
Multi-Vessel Electrostatic Precipitator dry type

- electricity recovery is improved by $30 \%$ annually compared with wet type

- energy consumption to be reduced by approx. $6.5 \times 10^{5} \mathrm{GJ}$ annually 